\title{
Over the Counter Product
}

National Cancer Institute

\section{Source}

National Cancer Institute. Over the Counter Product. NCI Thesaurus. Code C54068.

A medicine or device that can be bought without a doctor's order or prescription. 